\title{
ACE inhibitors predict for acute kidney injury during chemoradiation for head and neck cancer
}

\author{
Michael T. Spiotto ${ }^{a, b,{ }^{*}}$, Hongyuan $\mathrm{Cao}^{c}$, Loren Mell ${ }^{\mathrm{d}}$, and F. Gary Toback, MD, PhD \\ aDepartment of Radiation and Cellular Oncology, University of Chicago Medical Center, Chicago, \\ Illinois, 60612, United States \\ bDepartment of Radiation Oncology, University of Illinois Hospital and Health Sciences System, \\ Chicago, Illinois, 60637, United States \\ 'Department of Health Studies, University of Chicago, Chicago, Illinois \\ ${ }^{\mathrm{d}}$ Department of Radiation Oncology, University of California San Diego, San Diego, California \\ eDepartment of Medicine, University of Chicago, Chicago, Illinois 60637, United States
}

\begin{abstract}
Objecties-Head and neck cancer patients undergoing chemoradiation experience substantial toxicities including acute kidney injury (AKI). However, it remains unclear what factors predispose patients to renal toxicity during treatment. Here, we assessed the predictors and outcomes of patients experiencing AKI during chemoradiation.
\end{abstract}

Methods-We performed a retrospective cohort study to assess the maximum changes in serum creatinine $(\mathrm{Cr})$ in 173 patients with stage III-IV head and neck cancer treated with chemoradiation between 1999 and 2012. We defined AKI as Cr increases $\geq 26.5$ micromol/L over the pretreatment baseline.

Results-AKI was associated with angiotensin-converting enzyme inhibitor (ACEI) use (33.0\% vs. $11.0 \% ; P=.0004)$ but no other medications or comorbidities. On multivariate analysis, ACEI use, weight loss $\geq 10 \%$ of body weight and performance status $\geq 70$ predicted for $\mathrm{Cr}$ increments $\geq$ $26.5 \mathrm{micromol} / \mathrm{L}$, while only ACEI use predicted for $\mathrm{Cr}$ increments of $\geq 44.2 \mathrm{micromol} / \mathrm{L}$ or greater. Furthermore, on multivariate analysis, AKI predicted for more interventions during radiotherapy including intravenous fluid use $(P=.0005)$ and hospitalizations $(P=.007)$, as well as long term renal dysfunction $(P<.0001)$. Renal toxicity was not associated with worse locoregional control, progression free survival or overall survival.

Conclusions-Renal toxicity during chemoradiation was associated with ACEI use alone or coupled with weight loss $\geq 10 \%$ of body weight during therapy. Our results suggest that actively managing ACEI use and intravascular volume status during chemoradiation may avoid AKI, minimize subsequent interventions and reduce the risk for long term renal dysfunction.

*Corresponding Author: Michael T. Spiotto, Department of Radiation and Cellular Oncology, The University of Chicago, KCBD 6142, 900 E. $5^{\text {th }}$ St., Chicago, IL 60637, United States, Phone: 773-702-2751, Fax: 773-702-1968, mspiotto@ radonc.uchicago.edu. Financial Disclosures: None.

Conflicts of Interest: None. 


\section{Keywords}

Cancer of Head and Neck; Angiotensin Converting Enzyme Inhibitors; Acute Kidney Injury; Concurrent Chemoradiotherapy

\section{INTRODUCTION}

Multiple randomized control trials and meta-analyses have established platin-based chemoradiation for the treatment of locally advanced head and neck squamous cell cancers (HNSCC) [1-3]. Since many HNSCCs are associated with extensive smoking and alcohol histories, patients undergoing treatment also have multiple comorbidities associated with broad medication use [4]. As platin-based chemoradiation can also induce substantial toxicities during treatment, these existing comorbidities and their associated medications may conspire to exacerbate complications and adversely affect the outcomes of HNSCC patients.

One well established toxicity of platin-based chemoradiation is nephrotoxicity which may be accentuated in patients undergoing chemoradiation for head and neck cancer. Randomized control trials using cisplatin-based chemoradiation have reported Grade $\geq 3$ nephrotoxicity rates ranging from $4 \%$ to $8 \%$ during treatment $[1,2]$. Existing conditions such as congestive heart failure and diabetes may predispose the kidneys to additional nephrotoxic insults. Furthermore, chemoradiation causes mucositis and, subsequently, dehydration in patients thereby laying the foundation for iatrogenic pre-renal azotemia [5]. Since cisplatin is metabolized to a nephrotoxin in kidney proximal tubular epithelial cells [6], medications may also interfere with this enzymatic pathway to potentiate renal toxicity during chemoradiation. However, it remains unclear how these pre-existing conditions and associated medication usages may predispose patients to renal toxicity during platin-based chemoradiation for HNSCCs.

Here, we assessed which medications and comorbidities, as well as tumor and treatment characteristics, predisposed HNSCC patients to acute kidney injury (AKI) and the impact of AKI on subsequent interventions during treatment, overall tumor control, and long term renal function.

\section{PATIENTS AND METHODS}

\section{Study Population}

We utilized a retrospective database of 803 patients with HNSCC to select 173 patients with Stage III-IVB disease treated with concurrent platin-based chemoradiation. Patients were treated at the University of Illinois Medical Center at Chicago between 1999 to 2012 and were analyzed under University of Illinois Medical Center IRB protocol 2011-1075 in accordance with the ethical standards of the responsible committee on human experimentation and with the Helsinki Declaration of 1999, as revised in 2000. Patients were excluded who did not have documented measurements of serum creatinine $(\mathrm{Cr})$ concentrations prior to, during and/or after treatment. All patients were treated with concurrent platin-based chemoradiation regimens: 118 patients received cisplatin, 53 
patients received carboplatin and 4 patients initially received cisplatin and were switched to carboplatin. During radiotherapy, acute toxicities were recorded during weekly on-treatment visits.

\section{Variables}

Data was collected from all available physical and electronic medical records. $\mathrm{Cr}$ values were obtained from patient records and were measured at the start of therapy, during radiotherapy at 1-2 week intervals and at regular follow-up visits. We defined renal toxicity as a peak $\mathrm{Cr}$ concentration during radiotherapy greater than or equal to $26.5 \mathrm{micromol} / \mathrm{L}$ over pretreatment $\mathrm{Cr}$ levels and denoted it as $\Delta \mathrm{Cr} \geq 26.5 \mathrm{micromol} / \mathrm{L}$. The peak $\mathrm{Cr}$ concentration was chosen to minimize bias in assessing kidney function. First, $\mathrm{Cr}$ measurements were chosen to assess renal injury because this objective measurement of renal function was most accessible in the patients' medical record. A Cr rise of $\geq 26.5$ micromol/L was used because it is one of the three Acute Kidney Injury Network (AKIN) criteria for AKI [7] and Cr increments as small as 26.5 to 44.2 micromol/L have been associated with increased mortality [8]. Furthermore, we did not use glomerular filtration rates (GFRs) to assess renal toxicity due to the difficulty of measuring GFR in non-steady state conditions [9], the intersubject variability with $\mathrm{Cr}$ clearance equations [10] and the difficulty in obtaining all factors to assess GFR from the patient's record at specific time points. To define long term renal dysfunction, we assessed increments in $\mathrm{Cr}$ concentration $\geq$ $26.5 \mathrm{micromol} / \mathrm{L}$ at last follow-up or at time of treatment failure compared to pre-treatment $\mathrm{Cr}$ levels. All patients were included in analysis regardless of treatment compliance. We approximated comorbidity burden using a modified Charlson Comorbidity Index [11] and performance status using the Karnofsky Performance Status (KPS) [12]. Staging was categorized using the American Joint Committee staging system at the time of diagnosis. Time to local control (LC), regional control (RC), progression free survival (PFS), and overall survival (OS) were determined from last date of RT. Patterns of failure were determined as the first failure with any component of local, regional or distant recurrence, respectively. PFS was calculated as the time to any failure or death. OS was calculated as the time to death.

\section{Statistical analysis}

We used JMP version 10 (SAS Institute) to perform statistical analysis using two-sided tests and defining significance as $P<.05$. Discrete variables were compared with the chi-square test and differences in the medians were assessed using the Wilcoxon test. Survival curves were plotted using the Kaplan-Meier method and significance was assessed using the Log Rank test. For univariate and multivariate analyses, we used Cox proportional hazard or logistic regression models to compare differences in survival or differences in categorical variables, respectively. Censoring is assumed to be non-informative. Variables with $P$ value $<.1$ on univariate analysis were included on multivariate analysis. Assumptions for nominal logistic regression were verified using the Hosmer-Lemeshow goodness-of-fit test. Patient characteristics that were not recorded were not included during statistical analysis. 


\section{RESULTS}

\section{Population, Tumor and Treatment Characteristics}

As shown in Table 1, median follow-up did not differ significantly between groups (24.8 months for $\mathrm{Cr}<26.5 \mathrm{micromol} / \mathrm{L}$ and 18 months for $\mathrm{Cr} \geq 26.5 \mathrm{micromol} / \mathrm{L} ; P=.83$ ). Patients experiencing renal toxicity were younger (55.6y vs. 59.9y; $P=.007)$ and had better performance status that approached statistical significance $(87.9 \%$ vs. $75.6 \% ; P=.05)$. There was no difference in gender, comorbidity scores, smoking or alcohol use, primary site, tumor stage or nodal stage. Patients had no differences in specific comorbidities such as chronic renal failure, congestive heart failure, diabetes or diabetic end organ damage (Table 2). Patients experiencing renal toxicity had significantly more angiotensin-converting enzyme inhibitor (ACEI) use (33.0\% vs. $11.0 \% ; P=.0004)$ but no other differences in the use of diuretics or other medications. As shown in Table 3, more patients experiencing renal toxicity had increased weight loss $\geq 10 \%$ of body weight during radiotherapy (64.8\% vs. $47.6 \% ; P=.008)$ and were treated with cisplatin $(78.0 \%$ vs. $60.2 \% ; P=.02)$. Fewer patients underwent postoperative radiotherapy $(42.7 \%$ vs. $27.5 \% ; P=.04)$.

\section{Predictors of $\mathrm{Cr}$ elevation}

As ACEI use, weight loss, cisplatin chemotherapy, post-operative radiotherapy and performance status were significantly different between cohorts, we assessed which factors were associated with renal toxicity during radiotherapy (Table 4). Increments in $\mathrm{Cr} \geq 26.5$ micromol/L were associated with ACEI use (OR 5.20; 95\% CI 2.01-15.10; $P=.004$ ), weight loss $\geq 10 \%$ of body weight (OR 2.33; 95\% CI 1.09-5.12; $P=.03$ ), and KPS $\geq 70$ (OR 8.38; 95\% CI 1.40-160.75; $P=.02$ ). Interestingly, only ACEI use remained significant for further incremental $\mathrm{Cr}$ rises of $\geq 44.2 \mathrm{micromol} / \mathrm{L}$ or greater.

\section{Outcomes and Toxicity}

As shown in Figure 1, declining renal function was not associated with worse locoregional control $(P=.98)$, progression free survival $(P=.62)$ or overall survival $(P=.12)$. On univariate analysis (Table 5), Cr elevations $\geq 26.5 \mathrm{micromol} / \mathrm{L}$ were associated with more intravenous fluid interventions during RT (OR 4.39; 95\% CI 2.33-8.50; $P<.0001$, and long term $\mathrm{Cr}$ rises $226.5 \mathrm{micromol} / \mathrm{L}$ (OR 5.31; 95\% 2.45-12.58; $P<.0001$ ). While hospitalizations were not significantly associated with $\mathrm{Cr} \geq 26.5 \mathrm{micromol} / \mathrm{L}$, hospitalizations were significantly associated with more marked Cr elevations of $\geq 44.2$ micromol/L. Furthermore, rates of hospitalizations for AKI were significantly higher in patients with Cr elevations $226.5 \mathrm{micromol} / \mathrm{L}(13.2 \%$ vs. $0.0 \% ; P<.0001)$. By contrast, acute toxicities such as requiring a feeding tube during or after RT, mucositis and dermatitis were not associated with an increment in Cr. On multivariate analysis (Table 6), hospitalizations were significantly associated with a rising Cr during RT (OR: 3.54; 95\% CI 1.41-9.70; $P=.007$ ) and cisplatin use (OR: 2.85; 95\% CI 1.13-7.66; $P=.03$; Table 6). Intravenous fluid use during RT was associated with Cr rises during RT (OR: 4.37 ; $95 \% \mathrm{CI}$ $1.89-10.57 ; P=.0005$ ) and weight loss $\geq 10 \%$ of body weight (OR: 3.34 ; 95\% CI 1.44 4.86; $P=.005$ ). Long term $\mathrm{Cr}$ elevations, which serve as a surrogate for chronic renal dysfunction, were also associated with $\mathrm{Cr}$ rises during RT. 


\section{DISCUSSION}

Here, we find that AKI during chemoradiation for HNSCC was associated with ACEI use, a greater than $10 \%$ loss of body weight, more frequent administration of intravenous fluids and hospitalizations. Multiple other medications used by these patients and/or their comorbidities were not associated with renal toxicity. Furthermore, kidney dysfunction during chemoradiation in these patients did not impact disease control or survival. Since ACEI use and/or weight loss were not associated with hospitalizations, intravenous fluid administration or long term renal dysfunction, our observations suggest a scenario in which decreased fluid intake during chemoradiaton resulted in intravascular volume depletion as measured by weight loss. When patients also take an ACEI, these states of intravascular volume depletion predisposed them to develop AKI leading to additional interventions during treatment and subsequent renal dysfunction. Therefore, aggressive monitoring and management of ACEI use and intravascular volume status during chemoradiation for HNSCC may avoid renal toxicity during treatment and their associated early and late sequellae.

ACEI use and weight loss during chemoradiation likely combined to cause renal toxicity by creating a condition of "functional renal insufficiency" [13]. Under conditions of volume depletion, the angiotensin converting enzyme (ACE) normally converts angiotensin I (Ang I) to angiotensin II (Ang II) to maintain glomerular capillary pressure by constricting the efferent arteriole to a greater extent than the afferent arteriole. The ACEI blocks the conversion of Ang I to Ang II thereby preventing the kidney from maintaining adequate renal perfusion during hypovolemic conditions resulting in diminished glomerular filtration marked by a rising $\mathrm{Cr}$. Since weight loss is a surrogate for volume depletion during chemoradiation, it is consistent that use of an ACEI and weight loss correlated with renal toxicity (Table 4). However, ACEI use, but not weight loss was significantly associated with increased $\mathrm{Cr} \geq 44.2 \mathrm{micromol} / \mathrm{L}$ suggesting that the ACEI may potentiate renal dysfunction even during states of minimal volume depletion in this setting. Similarly, other studies found that patients on an ACEI were predisposed to AKI when other instigators of volume depletion such as diuretics were initiated [14]. Our findings contrast with reports showing ACEI having nephroprotective effects in patients with chronic renal failure [15] as well as congestive heart failure (CHF) [16, 17] likely by improving renal blood flow. However, 2$4 \%$ of CHF patients taking an ACEI did experience decreased renal function, likely due to states of "functional renal insufficiency", which is consistent with our observations [18, 19]. ACEI have been shown to have radiosensitizing effects [20] as well as the capacity to protect against radiation pneumonitis [21] and nephropathy [22]. Still, we did not observe that ACEI impacted disease control in our patients. Thus, our data suggests that use of an ACEI may predispose patients to renal toxicity during concurrent chemoradiation, especially when intravascular volume loss occurs.

While ACEI use was associated with renal toxicity, it was not observed with other medications or comorbidities. Specifically, diuretics were not significantly associated with Cr elevations suggesting that renal dysfunction during chemoradiation was not solely due to intravascular volume depletion. Lin et al. showed a significant correlation between weight loss and renal toxicity [5] but the correlation coefficient, $r$, was 0.4 suggesting that other 
factors, such as medications, and may also play a role. Similarly, in patients treated with a cisplatin based regimen, Shord et al. suggested that agents which reduce intravascular volume status, such as the diuretic hydrochlorothiazide, were associated with renal toxicity [23]. However, this study was conducted in patients with metastatic cancer who were not predisposed to similar risks of dehydration as are patients with HNSCC undergoing curative radiotherapy. While only ACEI use significantly correlated with acute renal toxicity, we cannot exclude the possibility that diuretics played a minor role by inducing mild hypovolemia and/or hypotension.

$\mathrm{Cr}$ rises during radiotherapy were also associated with additional interventions including increased use of intravenous fluids and more hospitalizations as well as more long term renal dysfunction. These interventions during treatment predispose patients to additional complications and greater utilization of health care resources. Furthermore, long term renal toxicity may exacerbate existing medical conditions and subject patients to additional medical and/or invasive interventions. Thus, $\mathrm{Cr}$ rises as little as $26.5 \mathrm{micromol} / \mathrm{L}$ may impact patient outcomes by increasing interventions during chemoradiation and by increasing the risk of long term renal toxicity after treatment.

In our study, $\mathrm{Cr}$ rises and the associated toxicities occurring during chemoradiation did not adversely affect disease control or overall survival. The lack of difference in disease control with the higher $\mathrm{Cr}$ elevations may be due to the similar rates of radiotherapy delays or chemotherapy dose modifications regardless of whether patients experienced elevations in Cr. The lack of differences in chemotherapy dose modifications or radiotherapy delays may be due to the preponderance of other dose limiting toxicities such as neutropenia that overshadowed delays due to nephrotoxic insults. In addition, the similar rates of disease control are consistent with the direct tumoricidal actions of platin agents which remain distinct from the nephrotoxic platin metabolites. Furthermore, while AKI is associated with increased morbidity in the general population, it may not impact survival as much as cancer recurrence or other comorbid conditions that are frequently associated with head and neck cancer patients.

Our results are limited by the retrospective nature of this study. While our study cannot address the patient's medication compliance, we still observed a significant association of ACEI, even with further Cr elevations during chemoradiation. These observations indicated that ACEI use was significantly associated with more severe renal toxicity and was not likely influenced by issues of medication compliance. Second, it remains uncertain how great a role was played by the comorbidities of $\mathrm{CHF}$ and diabetes mellitus in our patient population. Minimally severe comorbidities may make it difficult to assess small but important contributions to renal toxicity. Furthermore, we may not have observed the impact of comorbidities on AKI because chemoradiation protocols often select patients with mild comorbidities in order to minimize adverse events. Third, we used a population with heterogeneous patient and treatment characteristics. Still, patients experiencing renal dysfunction had the same, if not better, prognostic characteristics, and any treatment differences were not significant on multivariate analysis. Finally, we only relied on serum $\mathrm{Cr}$ and did not use other parameters such as Cr clearance to assess renal function. Nevertheless, Cr levels were frequently assessed during chemoradiation and represent the standard 
biomarker used to assess renal function in the clinic. Despite the limitations of our study, we contend that there is a significant association between ACEI use with AKI during chemoradiation which is exacerbated in the setting of volume contraction manifested by weight loss.

In conclusion, we have identified several factors that predict renal toxicity and its sequellae in patients undergoing chemoradiation for head and neck cancer. Our data suggested that ACEI use alone or coupled with significant weight loss predisposed patients to AKI. Patients who developed renal toxicity during treatment required more intravenous fluid support, had a greater number of hospitalizations and had more marked renal dysfunction. However, renal toxicity likely did not impact disease control and overall survival. Thus, by monitoring ACEI use and avoiding volume contraction during radiotherapy, we may prevent short and long term renal toxicities and subsequent clinical interventions set in motion by these adverse events.

\section{Acknowledgments}

Funding: M.T.S. was supported by the Burroughs Wellcome Fund Career Award for Medical Scientists. F.G.T. was supported by NIH Grant R21 CA176032-01A1.

\section{Abbreviations}

$\begin{array}{ll}\text { AKI } & \text { acute kidney injury } \\ \text { ACEI } & \text { angiotensin-converting enzyme inhibitor } \\ \text { IMRT } & \text { intensity modulated radiotherapy } \\ \text { Cr } & \text { creatinine } \\ \text { GFR } & \text { glomerular filtration rate } \\ \text { Ang I } & \text { angiotensin I } \\ \text { Ang II } & \text { angiotensin II } \\ \text { HNSCC } & \text { head and neck squamous cell carcinoma } \\ \text { RT } & \text { radiotherapy } \\ \text { KPS } & \text { Karnofsky performance status } \\ \text { LC } & \text { local control } \\ \text { RC } & \text { regional control } \\ \text { OS } & \text { overall survival } \\ \text { PFS } & \text { progression free survival } \\ \text { UVA } & \text { univariate analysis } \\ \text { MVA } & \text { multivariate analysis }\end{array}$




\section{References}

1. Adelstein DJ, Li Y, Adams GL, Wagner H Jr, Kish JA, Ensley JF, et al. An intergroup phase III comparison of standard radiation therapy and two schedules of concurrent chemoradiotherapy in patients with unresectable squamous cell head and neck cancer. J Clin Oncol. 2003; 21:92-8. [PubMed: 12506176]

2. Forastiere AA, Goepfert H, Maor M, Pajak TF, Weber R, Morrison W, et al. Concurrent chemotherapy and radiotherapy for organ preservation in advanced laryngeal cancer. N Engl J Med. 2003; 349:2091-8. [PubMed: 14645636]

3. Pignon JP, Bourhis J, Domenge C, Designe L. Chemotherapy added to locoregional treatment for head and neck squamous-cell carcinoma: three meta-analyses of updated individual data. MACHNC Collaborative Group. Meta-Analysis of Chemotherapy on Head and Neck Cancer. Lancet. 2000; 355:949-55. [PubMed: 10768432]

4. Piccirillo JF. Importance of comorbidity in head and neck cancer. The Laryngoscope. 2000; 110:593-602. [PubMed: 10764003]

5. Lin A, Jabbari S, Worden FP, Bradford CR, Chepeha DB, Teknos TN, et al. Metabolic abnormalities associated with weight loss during chemoirradiation of head-and-neck cancer. International journal of radiation oncology, biology, physics. 2005; 63:1413-8.

6. Townsend DM, Deng M, Zhang L, Lapus MG, Hanigan MH. Metabolism of Cisplatin to a nephrotoxin in proximal tubule cells. Journal of the American Society of Nephrology : JASN. 2003; 14:1-10. [PubMed: 12506132]

7. Mehta RL, Kellum JA, Shah SV, Molitoris BA, Ronco C, Warnock DG, et al. Acute Kidney Injury Network: report of an initiative to improve outcomes in acute kidney injury. Critical care. 2007; 11:R31. [PubMed: 17331245]

8. Chertow GM, Burdick E, Honour M, Bonventre JV, Bates DW. Acute kidney injury, mortality, length of stay, and costs in hospitalized patients. Journal of the American Society of Nephrology : JASN. 2005; 16:3365-70. [PubMed: 16177006]

9. Pickering JW, Endre ZH. GFR shot by RIFLE: errors in staging acute kidney injury. Lancet. 2009; 373:1318-9. [PubMed: 19376434]

10. Donahue A, McCune JS, Faucette S, Gillenwater HH, Kowalski RJ, Socinski MA, et al. Measured versus estimated glomerular filtration rate in the Calvert equation: influence on carboplatin dosing. Cancer chemotherapy and pharmacology. 2001; 47:373-9. [PubMed: 11391850]

11. Charlson ME, Pompei P, Ales KL, MacKenzie CR. A new method of classifying prognostic comorbidity in longitudinal studies: development and validation. J Chronic Dis. 1987; 40:373-83. [PubMed: 3558716]

12. Karnofsky, DA.; Burchenal, J. The Clinical Evaluation of Chemotherapeutic Agents in Cancer. CMM, editor. Columbia Univ Press; 1949.

13. Schoolwerth AC, Sica DA, Ballermann BJ, Wilcox CS. Council on the Kidney in Cardiovascular D the Council for High Blood Pressure Research of the American Heart A. Renal considerations in angiotensin converting enzyme inhibitor therapy: a statement for healthcare professionals from the Council on the Kidney in Cardiovascular Disease and the Council for High Blood Pressure Research of the American Heart Association. Circulation. 2001; 104:1985-91. [PubMed: 11602506]

14. Mandal AK, Markert RJ, Saklayen MG, Mankus RA, Yokokawa K. Diuretics potentiate angiotensin converting enzyme inhibitor-induced acute renal failure. Clinical nephrology. 1994; 42:170-4. [PubMed: 7994935]

15. The GISEN Group (Gruppo Italiano di Studi Epidemiologici in Nefrologia). Randomised placebocontrolled trial of effect of ramipril on decline in glomerular filtration rate and risk of terminal renal failure in proteinuric, non-diabetic nephropathy. Lancet. 1997; 349:1857-63. [PubMed: 9217756]

16. Garg R, Yusuf S. Overview of randomized trials of angiotensin-converting enzyme inhibitors on mortality and morbidity in patients with heart failure. Collaborative Group on ACE Inhibitor Trials. JAMA : the journal of the American Medical Association. 1995; 273:1450-6. 
17. Yusuf S, Sleight P, Pogue J, Bosch J, Davies R, Dagenais G. Effects of an angiotensin-convertingenzyme inhibitor, ramipril, on cardiovascular events in high-risk patients. The Heart Outcomes Prevention Evaluation Study Investigators. N Engl J Med. 2000; 342:145-53. [PubMed: 10639539]

18. The CONSENSUS Trial Study Group . Effects of enalapril on mortality in severe congestive heart failure. Results of the Cooperative North Scandinavian Enalapril Survival Study (CONSENSUS). N Engl J Med. 1987; 316:1429-35. [PubMed: 2883575]

19. The SOLVD Investigators. Effect of enalapril on survival in patients with reduced left ventricular ejection fractions and congestive heart failure. N Engl J Med. 1991; 325:293-302. [PubMed: 2057034]

20. Jordan BF, Peeterbroeck J, Karroum O, Diepart C, Magat J, Gregoire V, et al. Captopril and Snitrosocaptopril as potent radiosensitizers: Comparative study and underlying mechanisms. Cancer letters. 2010; 293:213-9. [PubMed: 20144849]

21. Kharofa J, Cohen EP, Tomic R, Xiang Q, Gore E. Decreased risk of radiation pneumonitis with incidental concurrent use of angiotensin-converting enzyme inhibitors and thoracic radiation therapy. International journal of radiation oncology, biology, physics. 2012; 84:238-43.

22. Moulder JE, Fish BL, Cohen EP. Treatment of radiation nephropathy with ACE inhibitors and AII type-1 and type-2 receptor antagonists. Current pharmaceutical design. 2007; 13:1317-25. [PubMed: 17506717]

23. Shord SS, Thompson DM, Krempl GA, Hanigan MH. Effect of concurrent medications on cisplatin-induced nephrotoxicity in patients with head and neck cancer. Anti-cancer drugs. 2006; 17:207-15. [PubMed: 16428940] 

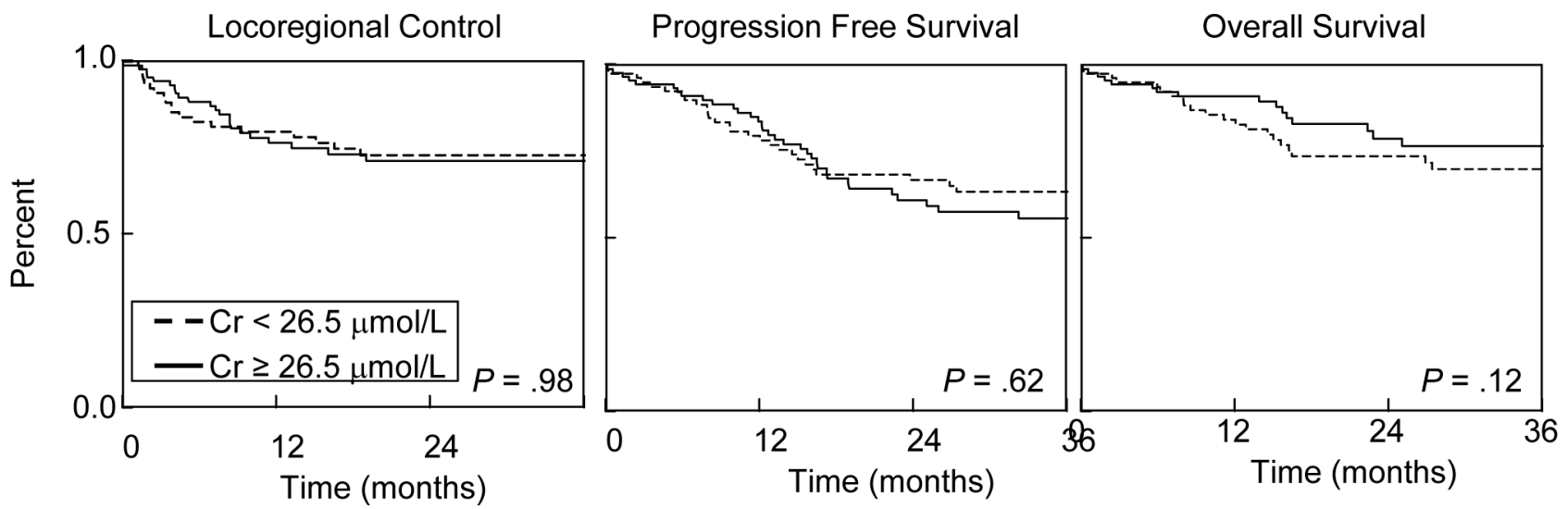

Figure 1. Kaplan-Meier analysis of outcomes in patients experiencing renal toxicity during chemoradiotherapy

(a) Locoregional control (b) progression free survival and (c) overall survival for Stage IIIIV HNSCC patients treated with chemoradiation. Solid line indicates patients having $\mathrm{Cr}$ rises $\geq 26.5 \mathrm{micromol} / \mathrm{L}$. Dashed line indicates patients having $\mathrm{Cr}$ rises $<26.5 \mathrm{micromol} / \mathrm{L}$. The log rank test was used to assess for differences in outcomes. 


\section{Table 1}

Patient Characteristics $n=173$

\begin{tabular}{|c|c|c|c|}
\hline & \multicolumn{2}{|c|}{$\mathrm{Cr}^{1}$ elevations during chemoradiation: } & \multirow[b]{2}{*}{ P value } \\
\hline & $\Delta \mathrm{Cr}<26.5 \mu \mathrm{mol} / \mathrm{L}(\mathrm{n}=82)$ & $\Delta \mathrm{Cr} \geq 26.5 \mu \mathrm{mol} / \mathrm{L}(\mathrm{n}=91)$ & \\
\hline Median age (years) $(\mathrm{IQR})^{2}$ & $59.9(50.1-68.2)$ & $55.6(50.4-65.1)$ & .007 \\
\hline Median follow-up (months) & $24.8(10.9-47.6)$ & $18(10.9-52.4)$ & .83 \\
\hline Gender & & & .10 \\
\hline Male & $57(69.5 \%)$ & $73(80.2 \%)$ & \\
\hline Female & $25(30.5 \%)$ & $18(19.8 \%)$ & \\
\hline $\mathrm{KPS}^{3}$ & & & .05 \\
\hline$\geq 70$ & $62(75.6 \%)$ & $80(87.9 \%)$ & \\
\hline$<70$ & $10(12.2 \%)$ & $1(1.1 \%)$ & \\
\hline Not stated & $10(12.2 \%)$ & $10(11.0 \%)$ & \\
\hline Comorbidity index & & & .11 \\
\hline Medium & $58(70.7 \%)$ & $54(59.4 \%)$ & \\
\hline High & $24(29.3 \%)$ & $37(40.7 \%)$ & \\
\hline Stage & & & .16 \\
\hline I & $1(1.2 \%)$ & $0(0.0 \%)$ & \\
\hline II & $3(3.7 \%)$ & $8(8.8 \%)$ & \\
\hline III & $25(30.5 \%)$ & $19(20.9 \%)$ & \\
\hline IV & $53(64.6 \%)$ & $64(70.3 \%)$ & \\
\hline Alcohol history & & & .85 \\
\hline 22 drinks/day & $38(46.3 \%)$ & $46(54.3 \%)$ & \\
\hline$<2$ drinks/day & $23(28.0 \%)$ & $26(28.6 \%)$ & \\
\hline Not stated & $21(25.6 \%)$ & $19(20.9 \%)$ & \\
\hline Tobacco history & & & .99 \\
\hline Yes (> 10 pack-years) & $61(74.3 \%)$ & $67(73.6 \%)$ & \\
\hline No ( $\leq 0$ pack-years) & $20(24.4 \%)$ & $22(24.2 \%)$ & \\
\hline Not stated & $1(1.2 \%)$ & $2(2.2 \%)$ & \\
\hline \multicolumn{4}{|l|}{ Primary site } \\
\hline Hypopharynx & $4(4.9 \%)$ & $3(3.3 \%)$ & .34 \\
\hline Larynx & $14(17.1 \%)$ & $24(26.4 \%)$ & \\
\hline Nasopharynx & $7(8.5 \%)$ & $8(8.8 \%)$ & \\
\hline Oral Cavity & $28(34.2 \%)$ & $19(20.9 \%)$ & \\
\hline Oropharynx & $20(24.4 \%)$ & $27(29.7 \%)$ & \\
\hline Other & $9(11.0 \%)$ & $10(11.0 \%)$ & \\
\hline Tumor Stage & & & .10 \\
\hline T0-2 & $22(26.8 \%)$ & $35(38.5 \%)$ & \\
\hline $\mathrm{T} 3-4 \mathrm{~b}$ & $60(73.2 \%)$ & $56(61.5 \%)$ & \\
\hline Nodal Stage & & & .53 \\
\hline NO-2a & $48(58.5 \%)$ & $49(53.9 \%)$ & \\
\hline
\end{tabular}




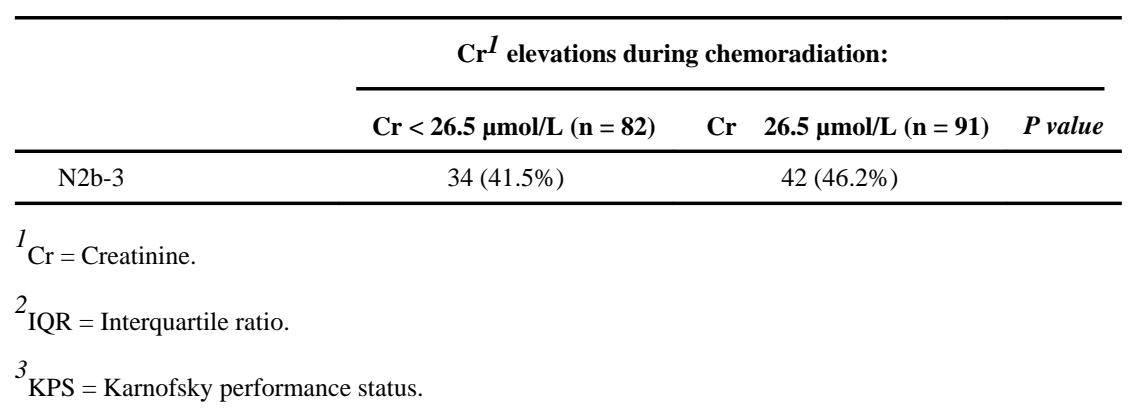


Table 2

Patient comorbidities and medication use $\mathrm{n}=173$

\begin{tabular}{|c|c|c|c|}
\hline & \multicolumn{2}{|c|}{ Cr elevations during chemoradiation: } & \multirow[b]{2}{*}{ P value } \\
\hline & $\Delta \mathrm{Cr}<26.5 \mu \mathrm{mol} / \mathrm{L}(\mathrm{n}=82)$ & $\Delta \mathrm{Cr} \geq 26.5 \mu \mathrm{mol} / \mathrm{L}(\mathrm{n}=91)$ & \\
\hline \multicolumn{4}{|l|}{ Comorbidities } \\
\hline \multicolumn{4}{|l|}{$\mathrm{DM}^{1}$ end organ damage } \\
\hline Yes & $1(1.2 \%)$ & $3(3.3 \%)$ & .35 \\
\hline No & $81(98.8 \%)$ & $88(96.7 \%)$ & \\
\hline \multicolumn{4}{|l|}{ DM } \\
\hline Yes & $9(11.0 \%)$ & $14(15.4 \%)$ & .39 \\
\hline No & $73(89.0 \%)$ & $77(84.6 \%)$ & \\
\hline \multicolumn{4}{|l|}{ Renal Failure } \\
\hline Yes & $4(4.8 \%)$ & $5(5.5 \%)$ & .86 \\
\hline No & $78(95.1 \%)$ & $86(94.5 \%)$ & \\
\hline \multicolumn{4}{|l|}{ Congestive heart failure } \\
\hline Yes & $3(3.7 \%)$ & $3(3.3 \%)$ & .90 \\
\hline No & $79(96.3 \%)$ & $88(96.7 \%)$ & \\
\hline \multicolumn{4}{|l|}{ Medications } \\
\hline $\mathrm{ACEI}^{2}$ & & & .0004 \\
\hline Yes & $9(11.0 \%)$ & $30(33.0 \%)$ & \\
\hline No & $73(89.0 \%)$ & $61(67.0 \%)$ & \\
\hline Diuretics & & & .62 \\
\hline Yes & $12(14.6 \%)$ & $12(13.2 \%)$ & \\
\hline No & $69(84.1 \%)$ & $79(86.8 \%)$ & \\
\hline Not stated & $1(1.2 \%)$ & $0(0.0 \%)$ & \\
\hline AngII receptor blocker & & & .26 \\
\hline Yes & $3(3.7 \%)$ & $1(1.1 \%)$ & \\
\hline No & $79(96.3 \%)$ & $90(989 \%)$ & \\
\hline Beta blocker & & & .80 \\
\hline Yes & $15(18.3 \%)$ & $18(19.8 \%)$ & \\
\hline No & $67(81.7 \%)$ & $73(80.2 \%)$ & \\
\hline Statin & & & .14 \\
\hline Yes & $11(13.4 \%)$ & $20(22.0 \%)$ & \\
\hline No & $71(86.6 \%)$ & $71(78.0 \%)$ & \\
\hline Calcium channel blocker & & & .19 \\
\hline Yes & $11(13.4 \%)$ & $19(20.9 \%)$ & \\
\hline No & $71(86.6 \%)$ & $72(79.1 \%)$ & \\
\hline Metformin & & & .10 \\
\hline Yes & $3(3.7 \%)$ & $9(9.9 \%)$ & \\
\hline No & $79(96.3 \%)$ & $82(90.1 \%)$ & \\
\hline Insulin & & & .11 \\
\hline
\end{tabular}




\begin{tabular}{|c|c|c|c|}
\hline & \multicolumn{2}{|c|}{ Cr elevations during chemoradiation: } & \multirow[b]{2}{*}{ Pvalue } \\
\hline & $\Delta \mathrm{Cr}<26.5 \mu \mathrm{mol} / \mathrm{L}(\mathrm{n}=82)$ & $\Delta \mathrm{Cr} \geq 26.5 \mu \mathrm{mol} / \mathrm{L}(\mathrm{n}=91)$ & \\
\hline Yes & $1(1.2 \%)$ & $5(5.5 \%)$ & \\
\hline No & $81(98.8 \%)$ & $86(94.5 \%)$ & \\
\hline
\end{tabular}

${ }^{1} \mathrm{DM}=$ Diabetes mellitus.

${ }^{2} \mathrm{ACEI}=$ angiotensin converting enzyme inhibitor. 


\section{Table 3}

Treatment characteristics $n=173$

\begin{tabular}{|c|c|c|c|}
\hline & \multicolumn{2}{|c|}{ Cr elevations during chemoradiation: } & \multirow[b]{2}{*}{$P$ value } \\
\hline & $\Delta \mathrm{Cr}<26.5 \mu \mathrm{mol} / \mathrm{L}(\mathrm{n}=82)$ & $\Delta \mathrm{Cr} \geq 26.5 \mu \mathrm{mol} / \mathrm{L}(\mathrm{n}=91)$ & \\
\hline $\mathrm{RT}^{l}$ timing & & & .04 \\
\hline Postoperative & $35(42.7 \%)$ & $25(27.5 \%)$ & \\
\hline Definitive & $47(57.3 \%)$ & $66(72.5 \%)$ & \\
\hline Induction chemotherapy & & & .10 \\
\hline Yes & $21(25.6 \%)$ & $34(37.4 \%)$ & \\
\hline No & $61(74.4 \%)$ & $57(62.2 \%)$ & \\
\hline Post-operative lymph node dissection & & & .39 \\
\hline Yes & $7(8.5 \%)$ & $14(15.4 \%)$ & \\
\hline No & $40(48.8 \%)$ & $52(57.1 \%)$ & \\
\hline Not stated & $35(42.7 \%)$ & $25(27.5 \%)$ & \\
\hline $\mathrm{IMRT}^{2}$ & & & .30 \\
\hline Yes & $72(87.8 \%)$ & $82(90.1 \%)$ & \\
\hline No & $8(9.8 \%)$ & $5(5.5 \%)$ & \\
\hline Not stated & $2(2.4 \%)$ & $4(4.4 \%)$ & \\
\hline \multicolumn{4}{|l|}{ Type of chemotherapy } \\
\hline Cisplatin & & & .02 \\
\hline Yes & $51(60.2 \%)$ & $71(78.0 \%)$ & \\
\hline No & $31(37.8 \%)$ & $20(22.0 \%)$ & \\
\hline Carboplatin & & & .11 \\
\hline Yes & $31(37.8 \%)$ & $24(26.4 \%)$ & \\
\hline No & $51(62.2 \%)$ & $67(73.6 \%)$ & \\
\hline Alterations in RT course & & & .68 \\
\hline None & $50(61.0 \%)$ & $50(55.0 \%)$ & \\
\hline Delay & $23(28.1 \%)$ & $31(34.1 \%)$ & \\
\hline Truncations & $9(11.0 \%)$ & $10(11.0 \%)$ & \\
\hline Chemotherapy dose modification & & & .53 \\
\hline Yes & $42(51.2 \%)$ & $51(56.0 \%)$ & \\
\hline No & $40(48.8 \%)$ & $40(44.0 \%)$ & \\
\hline Weight loss $\geq 10 \%$ of body weight & & & .008 \\
\hline Yes & $39(47.6 \%)$ & $59(64.8 \%)$ & \\
\hline No & $33(40.2 \%)$ & $20(22.0 \%)$ & \\
\hline Not stated & $10(12.2 \%)$ & $12(13.2 \%)$ & \\
\hline
\end{tabular}




\section{TABLE 4}

Multivariate analysis for factors impacting Creatinine rise during RT $\mathrm{n}=173$

\begin{tabular}{lccc}
\hline & \multicolumn{3}{c}{ Odds ratios for Cr elevations during chemoradiation $(\mathbf{9 5 \%} \mathbf{C I})$} \\
\cline { 2 - 4 } & $\Delta \mathbf{C r} \geq \mathbf{2 6 . 5} \boldsymbol{\mu \mathbf { m o l } / \mathbf { L }}$ & $\boldsymbol{\Delta} \mathbf{C r} \geq \mathbf{4 4 . 2} \boldsymbol{\mu m o l} / \mathbf{L}$ & $\Delta \mathbf{C r} \geq \mathbf{6 1 . 9} \boldsymbol{\mu m o l} / \mathbf{L}$ \\
\hline Post-operative RT & $0.59(0.28-1.25)$, & $0.96(0.45-2.05)$, & $0.79(0.34-1.75)$, \\
$P$ value & .17 & .93 & .56 \\
ACEI & $5.20(2.01-15.10)$ & $4.65(1.99-11.47)$ & $2.95(1.25-7.03)$, \\
$P$ value & .0004 & .0003 & .02 \\
Cisplatin & $2.26(0.99-5.40)$, & $3.81(0.65-72.93)$, & $2.48(0.41-47.38)$, \\
$P$ value & .05 & .16 & .36 \\
KPS $\geq 70$ & $8.38(1.40-160.75)$, & $1.52(1.69-3.44)$, & $1.42(0.62-3.42)$, \\
$P$ value & .02 & .30 & .41 \\
Weight loss $>10 \%$ & $2.33(1.09-5.12)$, & $1.52(0.69-3.44)$, & $1.42(0.62-3.43)$, \\
$P$ value & .03 & .30 & .41 \\
\hline
\end{tabular}

${ }^{1}$ Since increasing age likely predisposes to reduced renal function, age was not included in analysis as we observed that younger patients were more likely to experience $\mathrm{Cr}$ rises $\geq 26.5 \mathrm{micromol} / \mathrm{L}$. 
Table 5

Univariate analysis of outcomes and toxicities for Creatinine increases $n=173$

\begin{tabular}{|c|c|c|c|}
\hline & \multicolumn{3}{|c|}{ Hazard/Odds ratios during chemoradiation (95\% CI) } \\
\hline & $\Delta \mathrm{Cr} \geq 26.5 \mu \mathrm{mol} / \mathrm{L}$ & $\Delta \mathrm{Cr} \geq 44.2 \mu \mathrm{mol} / \mathrm{L}$ & $\Delta \mathrm{Cr} \geq 61.9 \mu \mathrm{mol} / \mathrm{L}$ \\
\hline $\mathrm{LRC}^{l}$ & $1.00(0.55-1.85)$ & $1.29(0.51-2.59)$ & $2.36(0.65-2.35)$ \\
\hline$P$ value & .98 & .51 & .48 \\
\hline $\mathrm{PFS}^{2}$ & $0.89(0.56-1.41)$ & $1.01(0.63-1.61)$ & $1.24(0.75-2.01)$ \\
\hline$P$ value & .62 & .95 & .39 \\
\hline $\mathrm{OS}^{3}$ & $0.63(0.34-1.13)$ & $0.83(0.44-1.50)$ & $0.91(0.45-1.72)$ \\
\hline$P$ value & .12 & .54 & .79 \\
\hline $\mathrm{IVF}^{4}$ during RT & $4.39(2.33-8.50)$ & $4.23(2.14-8.77)$ & $3.49(1.68-7.23)$ \\
\hline$P$ value & $<.0001$ & $<.0001$ & .0006 \\
\hline Hospitalizations & $1.86(0.98-3.57)$ & $2.70(1.34-5.65)$ & $2.25(1.06-5.01)$ \\
\hline$P$ value & .06 & .005 & .04 \\
\hline Feeding tube at start of RT & $0.87(0.43-1.78)$ & $0.75(0.35-1.56)$ & $0.78(0.33-1.69)$ \\
\hline$P$ value & .71 & .45 & .53 \\
\hline Feeding tube during RT & $1.64(0.90-3.02)$ & $1.61(0.87-2.99)$ & $1.57(0.81-3.07)$ \\
\hline$P$ value & .10 & .13 & .18 \\
\hline Grade $\geq 3$ Mucositis & $0.89(0.46-1.74)$ & $0.69(0.34-1.37)$ & $0.95(0.45-1.97)$ \\
\hline$P$ value & .73 & .29 & .90 \\
\hline Grade $\geq 3$ Dermatitis & $0.68(0.16-2.67)$ & $0.80(0.63-3.15)$ & $1.22(0.25-4.85)$ \\
\hline$P$ value & .58 & .75 & .79 \\
\hline Long term $\Delta \mathrm{Cr} \geq 26.5 \mu \mathrm{mol} / \mathrm{L}$ & $5.31(2.45-12.58)$ & $9.67(4.51-22.16)$ & $9.24(4.35-20.40)$ \\
\hline$P$ value & $<.0001$ & $<.0001$ & $<.0001$ \\
\hline \multicolumn{4}{|l|}{ l LRC = locoregional control. } \\
\hline \multicolumn{4}{|l|}{${ }^{2} \mathrm{PFS}=$ progression free survival. } \\
\hline
\end{tabular}


TABLE 6

Multivariate analysis for toxicity $n=173$

\begin{tabular}{|c|c|c|c|}
\hline & \multicolumn{3}{|c|}{ Odds Ratio (95\% Confidence Interval) } \\
\hline & Hospitalizations & Intravenous fluids during RT & Long term $\Delta \mathrm{Cr} \geq 26.5 \mu \mathrm{mol} / \mathrm{L}$ \\
\hline Cr rise during $\mathrm{RT}^{l}$ & 3.54 (1.41-9.70), & 4.37 (1.89-10.57), & $9.71(3.20-37.99)$ \\
\hline$P$ value & .007 & .0005 & $<.0001$ \\
\hline $\mathrm{ACEI}^{4}$ & $1.58(0.52-5.06)$ & $1.14(0.41-3.35)$ & $1.34(0.48-3.69)$ \\
\hline$P$ value & .42 & .80 & .57 \\
\hline Cisplatin & $2.85(1.13-7.66)$ & $1.99(0.81-5.00)$ & $1.51(0.51-4.91)$ \\
\hline$P$ value & .03 & .14 & .46 \\
\hline KPS $\geq 70$ & $1.32(0.28-7.56)$ & $0.47(0.09-2.20)$ & $0.86(0.10-18.60)$ \\
\hline$P$ value & .73 & .33 & .90 \\
\hline Weight loss $>10 \%$ & $1.90(0.81-4.57)$ & $3.34(1.44-8.02)$ & $1.02(0.36-2.97)$ \\
\hline$P$ value & .14 & .005 & .96 \\
\hline Post-operative RT & $0.77(0.33-1.76)$ & $2.01(0.87-4.86)$ & $1.12(0.43-2.87)$ \\
\hline$P$ value & .53 & .10 & .81 \\
\hline
\end{tabular}

